\title{
Laboreal
}

Volume $13 \mathrm{~N}^{\circ} 1$ | 2017

Varia

\section{Educación y actividad de trabajo: diálogos, obstáculos y desafíos - Preámbulo}

Educação e atividade de trabalho: diálogos, obstáculos e desafios - Preâmbulo

Éducation et activité de travail : dialogues, obstacles et défis - Préambule

Education and work activity: dialogues, barriers and challenges - Preamble

Alvaro Casas

\section{CpenEdition}

Journals

Edición electrónica

URL: http://journals.openedition.org/laboreal/1961

DOI: 10.4000/laboreal. 1961

ISSN: 1646-5237

Editor

Universidade do Porto

Referencia electrónica

Alvaro Casas, "Educación y actividad de trabajo: diálogos, obstáculos y desafíos - Preámbulo », Laboreal [En línea], Volume $13 N^{0} 1$ | 2017, Publicado el 01 julio 2017, consultado el 24 septiembre 2020. URL : http://journals.openedition.org/laboreal/1961 ; DOI : https://doi.org/10.4000/laboreal 1961

Este documento fue generado automáticamente el 24 septiembre 2020

\section{(1) (9)}

Laboreal está licenciado com uma Licença Creative Commons - Atribuição-NãoComercial 4.0 Internacional. 


\title{
Educación y actividad de trabajo: diálogos, obstáculos y desafíos - Preámbulo
}

\author{
Educação e atividade de trabalho: diálogos, obstáculos e desafios - Preâmbulo \\ Éducation et activité de travail : dialogues, obstacles et défis - Préambule \\ Education and work activity: dialogues, barriers and challenges - Preamble
}

\section{Alvaro Casas}

\section{NOTA DEL EDITOR}

http://dx.doi.org/10.15667/laborealxiii0117ac

\section{NOTA DEL AUTOR}

[1] Proyecto TR3S es un espacio de pensamiento y de vida, con una marcada orientación pedagógica, que articula siguiendo la composición de su sigla, a las categorías del trabajo, de la educación y de la sensibilidad. Ver más en https://www.facebook.com/ Tr3s.uy

[2] Para aquellos que quieran profundizar o actualizar los contenidos de esta conferencia, en particular lo que hace al contenido de la "segunda anticipación" sugerimos revisar el concepto de "saberes valores". (Ver Schwartz, 2015 y Schwartz, 2005).

1 Es un gran placer poder presentar este texto, que intuimos es una necesidad para Uruguay y para Iberoamérica. Es un gran honor porque se trata de una puerta que se abre en nuestros países para desarrollar una reflexión seria, rigurosa, sobre los procesos de trabajo, al ser la primera vez que la Ergología se presenta en un país de habla castellana/hispana. Es una necesidad porque la creciente visibilidad de los 
procesos de Educación y Trabajo en Uruguay, así como las tendencias en América Latina y el mundo, hacen que esta articulación se imponga como un tema de reflexión en la agenda actual. Intuimos -y usamos este verbo para no arrogarnos la pretensión del interés ajeno - que será de interés para los distintos actores de la formación profesional, para docentes, educadores, educadores sociales, profesionales diversos, gestores, empresarios, sindicatos, así como para el público en general.

2 Esta exposición fue realizada el día 5 de mayo de 2015, en el marco del Proyecto "Yves Schwartz en Uruguay", que implicó la participación del filósofo francés en una conferencia en la ciudad de Montevideo, otra en la ciudad de Maldonado y la realización de un curso de capacitación de "Introducción a la Ergología", también en la capital del país.

3 Las actividades fueron organizadas por Proyecto TR3S y contaron con la participación de unas 150 personas, contando con el auspicio de la Asociación de Educadores Sociales del Uruguay (ADESU), de la asociación civil Juventud para Cristo, del Centro Regional de Formación de Profesores del Este (CERP Este) y de la Universidad ORT[1].

4 Yves Schwartz ha desarrollado una corriente filosófica, una perspectiva denominada "Ergología", que centra su análisis en el concepto de actividad, analizándola desde un punto de vista histórico y conceptual, considerando de forma particular al trabajo como espacio de actividad.

5 Dimos con los planteos de Yves Schwartz a través de textos brasileños vinculados a la formación profesional (Nogueira Ramos, 2001), en los que su teoría emergía de forma clara y lúcida. Encontrar las categorías y el análisis propuesto por Yves Schwartz fue -y permítasenos usar la analogía- como encontrar una fuente de agua en medio de una ciudad que uno conoce por primera vez. De tanto caminar y caminar, de tanta avidez por conocer, la mente no se cansa, pero el cuerpo sí; sucede entonces que el visitante encuentra en el curso de un río, en la perspectiva del mar o en una fuente de agua, una excusa para parar, para sentarse, para observar y reflexionar.

6 Y fue precisamente un texto sobre los Ingredientes de la competencia laboral (Schwartz, 1997/1998) el primer texto escrito por el autor con el cual tomamos contacto y el que despertó nuestro interés, el que nos hizo parar, el que estudiamos y también disfrutamos.

7 Algo de ese texto se dibuja en el contenido de la conferencia que introducimos a continuación y que estuvo dirigida a estudiantes y egresados de la oferta formativa del Instituto de Educación de la Universidad ORT, así como a actores clave de la Formación Profesional y de la Educación Social en Uruguay.

8 La conferencia dice mucho acerca del concepto de Trabajo concebido como actividad, pero, ¿qué decir del lugar dado a la Educación en este contexto? Quisiéramos introducir dos reflexiones:

9 Cuando hablamos de "formación profesional" estamos hablando de "formación en relación al trabajo". Por tanto, comprender el trabajo, y no quedarnos en los lugares comunes en los que habitualmente se coloca al trabajo, se impone como una necesidad.

10 En segundo lugar, surge desde la conferencia que, a la hora de trabajar, los saberes incorporados en la educación operan en un marco de "debate de normas" del sujeto con su entorno. Es decir que "la primera anticipación" no remite sólo a saberes académicos, sino a todo tipo de normas que anteceden al aquí y el ahora de una persona en actividad. Ello implica entonces no sólo pensar al saber como una norma sino como una 
norma entre otras, a la hora de desarrollar actividad. Esta reflexión, que merece ser discutida entre educadores, pedagogos e investigadores requiere salir nuevamente del lugar común del concepto de "norma" para adentrarse en la conceptualización de sujeto implícita en la perspectiva ergológica. Invitamos entonces al lector "pedagógico" a adentrarse en la filosofía de Georges Canguilhem para profundizar en esta concepción, a quien Yves Schwartz menciona particularmente en la propia conferencia.

Por último, es dable aclarar que esta conferencia debe leerse en el contexto de una introducción de la Ergología en la sociedad uruguaya y en los países hispano parlantes. En este sentido, puede decirse que el planteo es menos filosófico que pragmático. La introducción de categorías como "doble anticipación", "ingredientes de la competencia" o la descripción de una experiencia «fundante», no buscan agotar la "gramática" ergológica ni la amplitud del pensamiento filosófico de Schwartz, sino que marcan pistas para introducir a la Ergología en los ámbitos académicos y sociales de nuestros países[2].

Queremos reconocer la participación de todas las instituciones ya mencionadas y de las personas que colaboraron de una u otra manera para la realización del proyecto que trajo a Yves Schwartz a Uruguay. En particular a todo el personal del Instituto de Educación de la Universidad ORT quien cedió las instalaciones para la realización de la conferencia. También deseamos resaltar el trabajo de transcripción realizado por la psicóloga colombiana Luisa Fernanda Delgado quien colaboró de forma muy profesional con el proyecto de publicación.

Nos tocó acompañar a Yves Schwartz en esta conferencia, apoyando en la traducción o en la aclaración de algunos significados. Si bien su lengua materna es el francés, él prefirió dictar la conferencia en español, refrescando una lengua que había practicado en su juventud; por ello el texto puede presentar imperfecciones de sintaxis o términos en "portuñol". Si bien la conferencia fue revisada y complementada por el autor y se han realizado los mayores esfuerzos por obtener el mejor producto posible, el texto puede presentar algún pasaje que no sea del todo claro para el lector.

En síntesis y hablando de traducciones, Yves Schwartz supo traducir nuestras inquietudes en la conferencia que aquí se transcribe y esperamos que muchos otros, en Iberoamérica y en los países hispano parlantes, puedan utilizar esta herramienta para traducir las propias.

15 En lo personal y desde proyecto Tr3s extiendo un cordial saludo a todos quienes se sientan identificados con el contenido del texto, deseando que nuestra intuición inicial se convierta en realidad.

\section{AUTOR}

\section{ALVARO CASAS}

Carrera Educador Social

Consejo de Formación en Educación - Administración Nacional de Educación Pública 
Salto 919 ap. 5, 11200, Montevideo, Uruguay alvaro.casas.gorgal@gmail.com 